\title{
Postpartum implanon/nexplanon uptake in a tertiary hospital in West Africa
}

\author{
Kwaku Asah-Opoku ${ }^{1 *}$, Kareem Mumuni ${ }^{1}$, Vincent J. Ganu², Ali Samba1
}

\begin{abstract}
${ }^{1}$ Department of Obstetrics and Gynecology, University of Ghana School of Medicine and Dentistry (UGSMD), KorleBu, Accra, Ghana

${ }^{2}$ Department of Medicine-Fevers Unit, Korle-Bu Teaching Hospital, Korle-Bu, Ghana
\end{abstract}

Received: 20 February 2019

Accepted: 01 April 2019

\section{*Correspondence:}

Dr. Kwaku Asah-Opoku,

E-mail: kasahopoku@yahoo.com

Copyright: () the author(s), publisher and licensee Medip Academy. This is an open-access article distributed under the terms of the Creative Commons Attribution Non-Commercial License, which permits unrestricted non-commercial use, distribution, and reproduction in any medium, provided the original work is properly cited.

\section{ABSTRACT}

Background: The postpartum period is viewed as an opportune period for uptake of contraception. Ghana has an unmet need for family planning of $30 \%$. This study sought to determine the postpartum Implanon/Nexplanon uptake among women at a tertiary hospital.

Methods: This was a retrospective study that analysed 391 Implanon/Nexplanon insertions between 2012 and 2015 at the reproductive health and family planning unit at the Korle-Bu teaching hospital.

Results: Almost 69\% (391/565) of all Implanon/Nexplanon insertions conducted between 2012 and 2015 were conducted in the postpartum period. Out of these postpartum insertions, $2.3 \%$ were done in the immediate postpartum period, $27.6 \%$ were done during the interval postpartum period and $70.1 \%$ were in the delayed postpartum period. Age and implant insertion status (first time ever or continuing) were significant determinants of postpartum Implanon/Nexplanon insertions. Compared to women less than 20 years of age, women in the age group 20-29 and 30-39 were 76\% (AOR=0.24, $\mathrm{CI}=0.62-0.97)$ and $80 \%(\mathrm{AOR}=0.20, \mathrm{CI}=0.05-0.86)$ respectively less likely to have postpartum Implanon/Nexplanon insertions done. Continuing users of implant insertions were $45 \%(\mathrm{AOR}=0.55$, $\mathrm{CI}=0.37-0.82$ ) less likely to have post-partum Implanon/Nexplanon insertions done compared to first ever users.

Conclusions: There is a high uptake of postpartum Implanon/Nexplanon use among patients who receive implant insertions at the Korle-Bu Teaching Hospital. However immediate postpartum Implanon/Nexplanon insertions are low. There is the need to educate women and couples on the benefits of immediate postpartum implant insertion to avoid rapid repeat pregnancies.

Keywords: Etonorgestrel containing implant, Extended postpartum, Delayed, Immediate, Implanon/Nexplanon, Uptake

\section{INTRODUCTION}

The World Health Organization has recommended a birth to pregnancy interval of 2 years. ${ }^{1}$ About $20 \%$ of pregnancies in developing countries occur less than 2 years after the preceding one. ${ }^{2}$ The burden of unintended pregnancies in developing countries is high. Close to $40 \%$ of all pregnancies in developing countries are unintended..$^{3,4}$
The uptake of effective contraception helps to reduce this burden and improve maternal and child health. ${ }^{5,6}$ Over 1.8 million unintended pregnancies could be prevented over a 5-year period with use of contraceptive implants. ${ }^{7}$ The postpartum period is viewed as an opportune period for uptake of contraception as new mothers make contact with health facilities. Long acting reversible contraceptives (LARC) such as the Etonorgestrel 
containing implant (Implanon/Nexplanon) have been found to be safe and efficacious. ${ }^{8,9}$

Data from some countries have shown that postpartum contraception constitutes a significant proportion of modern contraceptive uptake. ${ }^{10}$ Ghana has an unmet need of family planning of $30 \% .^{11}$ There is paucity of data on the uptake of postpartum Etonorgestrel containing implant and its determinants in the sub-region. Data on postpartum Etonorgestrel containing implant uptake will be very useful information for future planning in our efforts at reducing the high unmet need for family planning.

This study therefore sought to determine the uptake of postpartum Implanon/Nexplanon as well as determinants of these insertions among women.

\section{METHODS}

This was a retrospective study that analysed extended postpartum Implanon/Nexplanon uptake at the reproductive health and family planning unit at the KorleBu Teaching Hospital between 2012 and 2015. Data were extracted from the Unit's data storage system that captures all procedures undertaken at the unit. Data captured included total number of Implanon/Nexplanon insertions over the period, total number of Implanon/Nexplanon uptake and socio-demographic and obstetric determinants of uptake of postpartum Etonorgestrel containing implant.

The extended postpartum period was defined as the period from delivery of baby to one year post delivery. The extended post-partum period was categorized into the immediate (0-2 days post-partum), interval (3-42 days post-partum) and delayed (43-365 days post-partum).

\section{Statistical Analysis}

The extracted data was entered into Microsoft Office Excel 2010, cleaned and then exported into the IBM Statistical Package for Social Science (SPSS) version 20. The data analysis was presented as: Descriptive statistics i.e. frequencies, means and median and tables and charts. The categorical outcomes were presented as percentages. Chi square test was performed on categorical data to test association between uptake of Implanon/Nexplanon and selected determinants. Multiple logistic regressions were used to determine any predictors of the implant uptake. In all the statistical procedure, a p-value of less than 0.05 was considered statistically significant.

\section{RESULTS}

A total of 565 postpartum Implanon/Nexplanon insertions were conducted from 2012 to 2015 . Approximately $69 \%$ (391/565) of these implant insertions were done during the extended postpartum period (Figure 1).
Table 1: Socio-demographic characteristics of women who were provided with postpartum Implanon/ Nexplanon at the Korle-bu teaching hospital, Accra, Ghana from 2012-2015.

\begin{tabular}{|l|l|}
\hline Variable & Frequency $(\%)$ \\
\hline Age group & $\mathbf{N}=\mathbf{3 9 1}$ \\
\hline$<20$ & $23(5.9)$ \\
\hline $20-29$ & $189(48.3)$ \\
\hline $30-39$ & $173(44.2)$ \\
\hline 40 and above & $6(1.5)$ \\
\hline Parity & $\mathbf{N}=\mathbf{3 9 1}$ \\
\hline P1 & $136(34.8)$ \\
\hline P2-P4 & $235(60.1)$ \\
\hline P5 and above & $20(5.1)$ \\
\hline Abortions & $\mathbf{N}=391$ \\
\hline 0 & $297(76.0)$ \\
\hline 1 & $52(13.3)$ \\
\hline 2 & $30(7.7)$ \\
\hline $3+$ & $12(3.1)$ \\
\hline Occupation & $\mathbf{N}=\mathbf{3 5 1}$ \\
\hline Professional & $119(33.9)$ \\
\hline Skilled & $64(18.2)$ \\
\hline Semi-skilled & $12(3.4)$ \\
\hline Trader & $104(29.6)$ \\
\hline Housewife & $8(2.3)$ \\
\hline Student & $23(6.6)$ \\
\hline Unemployed & $21(6.0)$ \\
\hline Educational level & $\mathbf{N = 3 4 9}$ \\
\hline No formal education & $27(7.7)$ \\
\hline Primary & $27(7.7)$ \\
\hline JHS & $98(28.1)$ \\
\hline SHS & $48(13.8)$ \\
\hline Vocational & $6(1.7)$ \\
\hline Tertiary & $143(41.0)$ \\
\hline Couple involvement & $\mathbf{N = 3 9 1}$ \\
\hline Yes & $7(1.8)$ \\
\hline No & $384(98.2)$ \\
\hline Status & $244(62.4)$ \\
\hline First ever & $147(37.6)$ \\
\hline Continuing & \\
\hline
\end{tabular}

Table 2: Timing of postpartum Implanon/Nexplanon uptake among women at the Korle-Bu Teaching Hospital, Accra, Ghana from 2012-2015.

\begin{tabular}{|ll|}
\hline $\begin{array}{l}\text { Timing of uptake of post- partum } \\
\text { implanon }\end{array}$ & Frequency (\%) \\
\hline Immediate post-partum & $9(2.3)$ \\
\hline Interval post-partum & $108(27.6)$ \\
\hline Delayed post-partum & $274(70.1)$ \\
\hline
\end{tabular}

The mean age of patients who had postpartum Implanon/Nexplanon insertions during the study period was $28.51 \pm 5.29$ years. The median parity was 2.0 with a range of $1-9$. 
Majority (41\%) of the patients had tertiary education and $28.1 \%$ having education up to the junior high school level (Table 1). Approximately $62 \%$ of the women were having their first ever post-partum Implanon/Nexplanon insertion (Table 1). Couple involvement for post-partum Implanon/Nexplanon insertions was only in $1.8 \%$ of the patients.
The rates of post-partum Implanon/Nexplanon intake ranged from $50 \%$ to $89.7 \%$ with the highest uptake rate occurring in 2013 (Figure 2). Almost $70 \%$ of post-partum Implanon/Nexplanon insertions were done in the delayed postpartum period with the least $(2.3 \%)$ done in the immediate postpartum period (Table 2).

Table 3: Socio-demographic determinants of postpartum Implanon/Nexplanon uptake among women at the KorleBu teaching hospital, Accra, Ghana from 2012-2015.

\begin{tabular}{|c|c|c|c|c|}
\hline \multirow[b]{2}{*}{ Variable } & \multicolumn{2}{|c|}{ Postpartum Uptake } & \multirow[b]{2}{*}{ OR (95\% C.I) } & \multirow[b]{2}{*}{$\operatorname{AOR}(95 \%$ C.I $)$} \\
\hline & $\begin{array}{l}\text { Yes } \\
\mathrm{N}=391\end{array}$ & $\begin{array}{l}\text { No } \\
N=174\end{array}$ & & \\
\hline \multicolumn{5}{|l|}{ Age group } \\
\hline$<20$ & $23(5.9)$ & $3(1.7)$ & 1 & \\
\hline $20-29$ & $189(48.3)$ & $76(43.7)$ & $0.32(0.10-1.12)$ & $0.24(0.62-0.97)$ \\
\hline $30-39$ & $173(44.2)$ & $80(46.0)$ & $0.28(0.08-0.97)$ & $0.20(0.05-0.86)$ \\
\hline 40 and above & $6(1.5)$ & $15(8.6)$ & $0.05(0.01-0.24)$ & $0.05(0.01-0.27)$ \\
\hline \multicolumn{5}{|l|}{ Parity } \\
\hline $\mathrm{P} 1$ & $136(34.8)$ & $42(24.1)$ & 1 & \\
\hline P2-P4 & $235(60.1)$ & $120(69.0)$ & $0.61(0.40-0.91)$ & $0.87(0.53-1.43)$ \\
\hline P5 and above & $20(5.1)$ & $12(6.9)$ & $0.52(0.23-1.14)$ & $1.71(0.61-4.78)$ \\
\hline Previous abortions & $N=94$ & $\mathrm{~N}=77$ & & \\
\hline 1 & $52(55.3)$ & $40(51.9)$ & 1 & \\
\hline 2 & $30(31.9)$ & $23(29.9)$ & $1.00(0.51-1.98)$ & $*$ \\
\hline $3+$ & $12(12.8)$ & $14(18.2)$ & $0.66(0.28-1.58)$ & $*$ \\
\hline Occupation & $\mathbf{N}=351$ & $\mathrm{~N}=171$ & & \\
\hline Professional & $119(33.9)$ & $32(18.7)$ & $2.30(1.04-5.09)$ & $2.36(0.85-6.55)$ \\
\hline Skilled & $64(18.2)$ & $35(20.5)$ & $1.13(0.51-2.53)$ & $1.37(0.56-3.38)$ \\
\hline Semi-skilled & $12(3.4)$ & $10(5.8)$ & $0.74(0.25-2.20)$ & $0.87(0.26-2.87)$ \\
\hline Trader & $104(29.6)$ & $71(41.5)$ & $0.91(0.43-1.93)$ & $1.28(0.54-3.04)$ \\
\hline Housewife & $8(2.3)$ & $4(2.3)$ & $1.24(0.31-4.95)$ & $0.90(0.20-4.04)$ \\
\hline Student & $23(6.6)$ & $6(3.5)$ & $2.37(0.76-7.37)$ & $1.23(0.34-4.46)$ \\
\hline Unemployed & $21(6.0)$ & $13(7.6)$ & 1 & \\
\hline Educational level & $\mathrm{N}=349$ & $\mathrm{~N}=169$ & & \\
\hline No formal education & $27(7.7)$ & $12(7.1)$ & 1 & \\
\hline Primary & $27(7.7)$ & $19(11.2)$ & $0.63(0.26-1.55)$ & $0.70(0.27-1.83)$ \\
\hline JHS & $98(28.1)$ & $61(36.1)$ & $0.71(0.34-1.51)$ & $0.74(0.33-1.67)$ \\
\hline SHS & $48(13.8)$ & $30(17.8)$ & $0.71(0.31-1.61)$ & $0.74(0.30-1.78)$ \\
\hline Vocational & $6(1.7)$ & $3(1.8)$ & $0.89(0.19-4.16)$ & $1.05(0.21-5.24)$ \\
\hline Tertiary & $143(41.0)$ & $44(26.0)$ & $1.44(0.68-3.09)$ & $1.25(0.47-3.29)$ \\
\hline Couple involvement & $\mathbf{N}=391$ & $\mathrm{~N}=174$ & & \\
\hline Yes & $7(1.8)$ & $2(1.1)$ & $1.57(0.32-7.62)$ & $1.26(0.24-6.62)$ \\
\hline No & $384(98.2)$ & $172(98.9)$ & 1 & \\
\hline Status & $\mathrm{N}=391$ & $\mathrm{~N}=174$ & & \\
\hline First ever & $244(62.4)$ & $74(42.5)$ & 1 & \\
\hline Continuing & $147(37.6)$ & $100(57.5)$ & $0.45(0.31-0.64)$ & $0.55(0.37-0.82)$ \\
\hline
\end{tabular}

Age and Implanon/Nexplanon insertion status (first time ever or continuing) were significant determinants of postpartum Implanon/Nexplanon insertions. Compared to women less than 20 years of age, women in the age group 20-29 were $76 \%$ less likely to have post-partum
Implanon/Nexplanon insertions done. Continuing users of Implanon/Nexplanon were $45 \%$ less likely to have postpartum implant insertions done compared to first ever postpartum implant inserters (Table 3 ). 


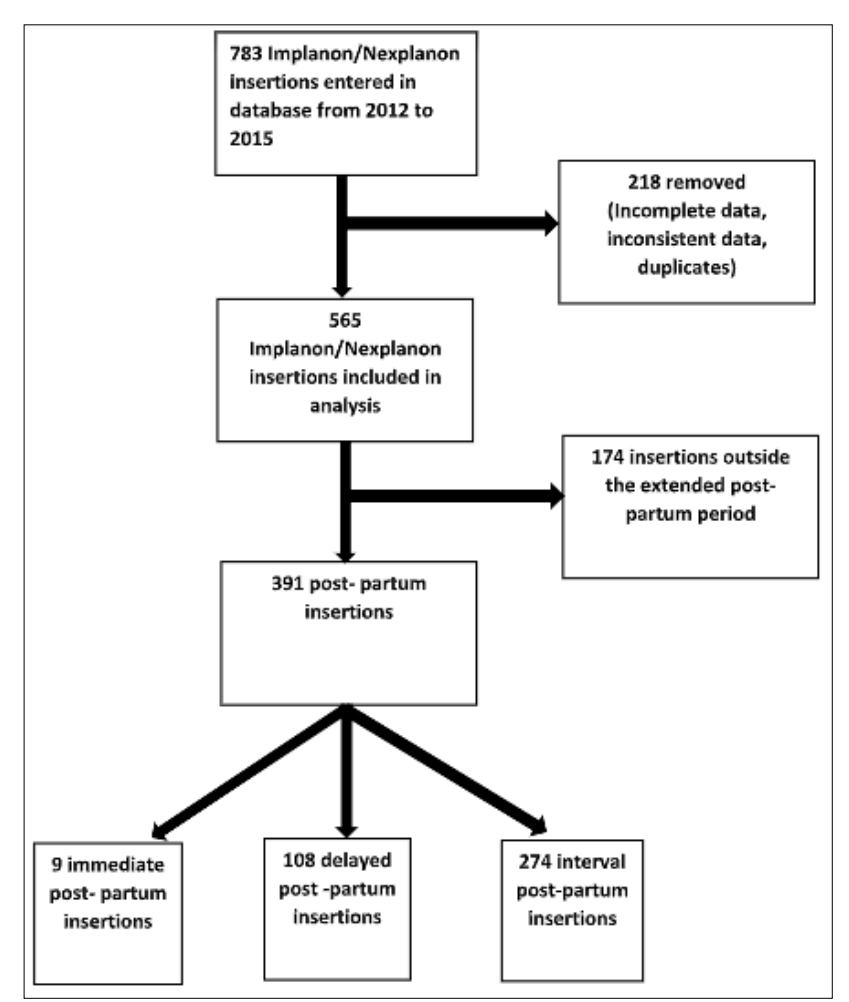

Figure 1: Flow chart.

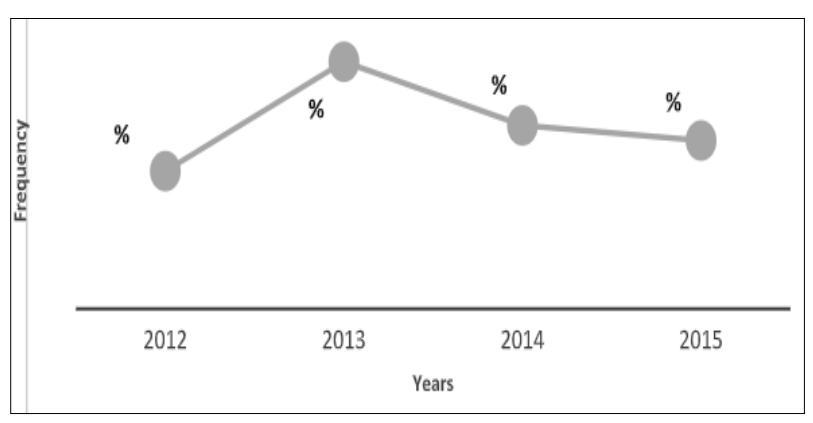

Figure 2: Postpartum imlplanon/Nexplanon uptake rates among women between 2012-2015 at Korle-Bu teaching hospital, Accra, Ghana.

\section{DISCUSSION}

Approximately $69 \%$ of postpartum Implanon/Nexplanon insertions were done during the extended postpartum period. The rates of postpartum Implanon/Nexplanon intake ranged from $50 \%$ to $89.7 \%$ with the highest uptake rate occurring in 2013. Almost $70 \%$ of post-partum Implanon/Nexplanon insertions were done in the delayed postpartum period with the least $(2.3 \%)$ done in the immediate post-partum period. Age and implant insertion status (first time ever or continuing) were significant determinants of postpartum implant insertions.

Immediate postpartum Implanon/Nexplanon use has not been found to have any deleterious health effects on the mother or baby ${ }^{8,9}$ It has also been associated with long term continuation rates and less cost. ${ }^{12,13}$ In a retrospective cohort study by Ireland et al, postpartum uptake of implanon during the immediate, delayed and interval period were $62.6 \%, 11.8 \%$ and $25.6 \%$ respectively. ${ }^{14}$ This finding is contrary to findings in our study where only $2.3 \%$ of postpartum Implanon/Nexplanon uptakes were in the immediate period. The reason for this could be due to poor counselling for post- partum implant use at the time. This constitutes a missed opportunity for women who will still be at the hospital and in touch with healthcare givers to take up Implanon/Nexplanon since the subsequent postpartum visits cannot be guaranteed. With the situation in Korle-Bu now, over the past 4 years, trained family planning midwives visit the post -partum wards to counsel women on contraception including postpartum implant use which can be delivered on site, this trend may improve in the near future. Bryant et al showed that with adequate provision of postpartum Implanon, the immediate postpartum Implanon is more likely to be accessed compared to the delayed. ${ }^{15}$

Concerning the determinants of uptake of postpartum Implanon/Nexplanon, teenagers were more likely to use postpartum Implant compared to other age groups. This is encouraging as it helps to prevent rapid repeat pregnancies among adolescents as reported in other studies. ${ }^{16,17}$ Postpartum Implanon use has been reported to be well accepted among adolescents. ${ }^{16-18}$ Though couple involvement was associated with about a quarter more uptake of postpartum Implanon/Nexplanon uptake this was not a significant finding in this study. This finding is similar to reports from other studies that partner involvement is important for uptake of modern contraception. ${ }^{19,20}$

Continuing users of Implanon/Nexplanon were $45 \%$ less likely to take up postpartum implant. This was a significant finding in this study. Previous experiences such as abnormal irregular bleeding whiles on implant may be the reason for this observation underscoring the need to counsel women thoroughly about what to expect when contraceptive methods are chosen. This finding is in contrast to another study where it was observed that subdermal implants in general have a high satisfaction uptake rates as well as continuation rates. ${ }^{21}$ This study however did not look specifically at this postpartum Implanon subgroup.

The highest uptake of postpartum Implanon/Nexplanon was in 2013 because a training workshop held in that year for healthcare givers on the Etonorgestrel insertions and removals with free insertions done during the period of the training. Cost of Implanon/Nexplanon therefore may be an inhibition to the uptake of these highly effective long acting reversible contraceptives.

\section{CONCLUSION}

There is a high uptake of postpartum Implanon/ Nexplanon among patients who receive Implant 
insertions at the Korle-Bu Teaching Hospital. There is the need to educate women and couples on the benefits and side effects of immediate postpartum Implant insertion to avoid rapid repeat pregnancies.

\section{ACKNOWLEDGMENTS}

Authors would like to thank to the staff of the reproductive health and family planning unit of the Korle-Bu Teaching Hospital for assisting us with the data collection. Authors gratitude to Maxfield Okere who assisted with cleaning up of the data and the analysis.

Funding: No funding sources

Conflict of interest: None declared

Ethical approval: The study was approved by the Institutional Ethics Committee

\section{REFERENCES}

1. World Health Organization. Birth Spacing. Geneva, Switzerland; 2005.

2. Rutstein SO. Effects of preceding birth intervals on neonatal, infant and under-five years mortality and nutritional status in developing countries: evidence from the demographic and health surveys. Int $\mathrm{J}$ Gynecol Obstet. 2005;89:S7-S24.

3. Sedgh G, Singh S, Hussain R. Intended and unintended pregnancies worldwide in 2012 and recent trends. Stud Fam Plann. 2014;45(3):301-14.

4. Bearak J, Popinchalk A, Alkema L, Sedgh G. Global, regional, and subregional trends in unintended pregnancy and its outcomes from 1990 to 2014: estimates from a Bayesian hierarchical model. Lancet Glob Heal. 2018;6(4):e380-9.

5. Sridhar A, Salcedo J. Optimizing maternal and neonatal outcomes with postpartum contraception: impact on breastfeeding and birth spacing. Matern Heal Neonatol Perinatol. 2017;3(1):1.

6. Ahmed S, Ahmed S, McKaig C. The effect of integrating family planning with a maternal and newborn health program on postpartum contraceptive use and optimal birth spacing in rural Bangladesh. Stud Fam Plann. 2015;46(3):297-312.

7. Hubacher D, Mavranezouli I, McGinn E. Unintended pregnancy in sub-Saharan Africa: magnitude of the problem and potential role of contraceptive implants to alleviate it. Contraception. 2008;78(1):73-8.

8. Brito MB, Ferriani RA, Quintana SM, Mehd Y, Silva de Sá MF, Vieira CS. Safety of the etonogestrelreleasing implant during the immediate postpartum period: a pilot study. Contraception. 2009;80(6):51926.

9. Gurtcheff SE, Turok DK, Stoddard G, Murphy PA, Gibson M, Jones KP. Lactogenesis after early postpartum use of the contraceptive implant. Obstet Gynecol. 2011;117(5):1114-21.

10. Eggebroten J. Patient uptake and outcomes: an immediate postpartum IUD and implant program. Obstet Gynaecol. 2016;127(5):2016.

11. Ghana statistical service (GSS), Ghana Health Service (GHS), and ICF Macro International 2009. Ghana Demographic and Health Survey. 2014.

12. Wilson S, Tennant C, Sammel MD, Schreiber C. Immediate postpartum etonogestrel implant: a contraception option with long-term continuation. Contraception. 2014;90(3):259-64.

13. Gariepy AM, Duffy JY, Xu X. Cost-effectiveness of immediate compared with delayed postpartum etonogestrel implant insertion. Obstet Gynecol. 2015;126(1):47-55.

14. Ireland LD, Goyal V, Raker CA, Murray A, Allen RH. The effect of immediate postpartum compared to delayed postpartum and interval etonogestrel contraceptive implant insertion on removal rates for bleeding. Contraception. 2014;90(3):253-8.

15. Bryant AG, Bauer AE, Stuart GS, Levi EE, Zerden ML, Danvers A, et al. Etonogestrel-releasing contraceptive implant for postpartum adolescents: a randomized controlled trial. J Pediatr Adolesc Gynecol. 2017;30(3):389-94.

16. Tocce KM, Sheeder JL, Teal SB. Rapid repeat pregnancy in adolescents: do immediate postpartum contraceptive implants make a difference? Am J Obstet Gynecol. 2012;206(6):481.e1-481.e7.

17. Han L, Teal SB, Sheeder J, Tocce K. Preventing repeat pregnancy in adolescents: Is immediate postpartum insertion of the contraceptive implant cost effective? Am J Obstet Gynecol. 2014;211(1):24.e1-24.e7.

18. Guazzelli CAF, De Queiroz FT, Barbieri M, Torloni MR, De Araujo FF. Etonogestrel implant in postpartum adolescents: Bleeding pattern, efficacy and discontinuation rate. Contraception. 2010;82(3):256-9.

19. Wulifan JK, Brenner S, Jahn A, De Allegri M. A scoping review on determinants of unmet need for family planning among women of reproductive age in low and middle income countries. BMC Womens Health. 2016;16:1-15.

20. Balogun O, Adeniran A, Fawole A, Adesina K, Aboyeji A, Adeniran P. Effect of male partner's support on spousal modern contraception in a low resource setting. Ethiop $J$ Health Sci. 2016;26(5):439.

21. Peipert JF, Zhao Q, Allsworth J, Petrosky E, Madden Tessa, Eisenberg D, et al. Continuation and satisfaction of reversible contraception. Obstetrics Gynecol. 2013;117(5):1105-13.

Cite this article as: Asah-Opoku K, Mumuni K, Ganu VJ, Samba A. Postpartum implanon/nexplanon uptake in a tertiary hospital in West Africa. Int $\mathbf{J}$ Reprod Contracept Obstet Gynecol 2019;8:1816-20. 